\title{
The Research on Vulnerability Measure for China's Tourism Economy System Based on SPA
}

\author{
YU SuJiao ${ }^{1, a}$ \\ ${ }^{1}$ School of continuing education, Qinghai university, xining 810001,China \\ ayusujiao@163.com
}

Keywords: Set Pair Analysis Method; Tourism Economy; Vulnerability

\begin{abstract}
Tourism industry belongs to the typical sensitive sectors, very vulnerable to changes in the internal and external environment, and on the basis of the tourism resources development model largely limits the transformation of urban industry, make the urban economic system lack of coping capacity. Especially under the background of globalization, tourism city economy system to the world economic turmoil, epidemics, natural disasters and other events are very sensitive, so tourist city economic system has obvious characteristic of vulnerability. In tourism in the process of urban development, therefore, must to tourist city economy system vulnerability of high attention. Article using set pair analysis method, from the sensitivity of the tourism economy system and deal with two aspects of constructing the index system.
\end{abstract}

\section{Introduction}

Tourism economy system Vulnerability (Vulnerability) refers to a variety of factors, both inside and outside the system disturbance, the sensitivity and response capacity of the tourism economic system that of checks and balances the system structure and function of the attribute of a vulnerable, is a measure for the sustainable development of tourism economy. Fragility is the inverse problem of sustainable development, at present, our country has been positioning for the tourism industry. State strategic pillar industry and modern service industry. Therefore, in the tourism industry development, system vulnerability must give full attention to tourism economy [1-2].

Under the background of globalization, the shock wave of the world economy, the change of international political situation, natural disasters, epidemic disease, emergency, and the tourism crisis events, such as social unrest, will have an effect on sustainable tourism development [3]. Tourism economy in China has experienced more than 30 years of rapid development at the same time, also has experienced eight big tourism crisis events, the impact of tourism economic system also accumulated many contradictions, the fragility of the tourism economy system problem is also constantly exposed. Based on the potential risk of China's tourism economy system and the increasingly complex external development environment, choose the scientific method to judge the vulnerability of the tourism economy system in China, in order to carry on the effective regulation and to maintain continuous and stable development of tourism economy in our country, will have certain practical significance.

\section{Summary of set pair analysis method}

Set pair analysis is processing system for certainty and uncertainty of interaction between mathematics theory, put forward by Chinese scholars Ke-qin Zhao in 1989, the main mathematical tools is contact number, so far, the set pair analysis has been widely used, but the set pair analysis is still under development. Set pair is made of the basic unit of the connection of two collections. And set pair analysis and contact one of the most basic concept in mathematics, by Keion Zhao in 1989 formally put forward. Due to the rules set element in mathematics can be people, things, things, digital, and concept. Set pair analysis is under the background of a certain problem, two set of set pair of certainty and uncertainty, certainty and uncertainty of the interaction of a system and mathematical analysis. Usually include the set of two sets of characteristics, relation, structure, state, 
trend analysis, and connect mode; This analysis through the establishment of the theory of two connection number of set, sometimes also cannot contact with for analysis.2 set cooperation characteristics of set pair analysis, need to abstract the first set of two sets of their respective features, then compare these two collections on what features the same, what are the features, that is, at the same time; These two collections on which features, is contradictory and conflict on what features; And on the other some of the features of both different one, nor opposing such analysis [4].

Set pair analysis is not only applicable to only 2 sets of occasions, also are suitable for multiple sets of occasions, the need to write contact number for the two set of each first, again to get several contact number for proper operation and analysis, in order to solve a given problem. Set pair analysis also advocates starting from the intention of "set", advocating the same problem with two or more different methods, two or more different point of view, two or more times again and again to study, to integrate the results of the study, the final conclusion, to ensure that set pair analysis of the reliability and credibility. Thus, set pair analysis is the study and treatment of the complex system about the uncertainty problem of a system mathematical method. In some of the existing literature, also known as the set pair analysis contact mathematics, but says from the original meaning, there are difference between the two, the main difference lies in the set pair analysis can sometimes without contact number system mathematical analysis, but contact mathematics involved in the number of contact operation.

\section{The construction of index system}

Tourism economy system vulnerability mainly has three meanings: first, it shows that tourism economy system exists inherent instability; Second, the tourism economy system to the outside interference and change (natural or manmade) is more sensitive; Third, under the stress of outside interference and the external environment change, the system is vulnerable to a certain degree of loss or damage. Tourism economy system vulnerability is various, therefore, tourism economic indicators comprehensive properties, it contains two aspects of sensitivity and response. The sensitivity refers to the tourism economy system in case of internal disorder or by external shocks, shown under damage ability, the less sensitive sex, tourism economy system less vulnerable to damage, has a strong ability to resist. And tourism economy system response is letting tourism economy system from the crisis quickly adjust to security and stability conditions of ability, the stronger the response capacity, tourism economy system of self-maintenance, and the stronger the ability to adapt. Tourism economy system response capacity may come from outside, also may come from within the system, also may be internal or external force result of joint action [5]. To establish the tourist city of the economic system vulnerability evaluation index system as shown in table 1.

In a word, the sensitivity of the tourism economy system and deal with in the interaction, jointly determine the vulnerability of the tourism economy system. Tourism economic Vulnerability Curve can be presented by the relationship between available tourism economic sensitivity (s) and the response capacity. When the tourism economic vulnerability is larger, the tourism economy system under all kinds of crisis undermine the ability is poorer, tourism economic recovery to the steady state speed is slower, conversely tourism economy system more secure. Therefore, here from two aspects of sensitivity and response design system vulnerability evaluation index system of tourism economy. 
Table 1. Tourist city economy system vulnerability evaluation index system

\begin{tabular}{|c|c|c|c|c|c|}
\hline Target layer & Rule layer & Code & Indicators & Index weight & Index properties \\
\hline \multirow{15}{*}{$\begin{array}{c}\text { Economic } \\
\text { vulnerability } \\
\text { index system }\end{array}$} & \multirow{7}{*}{$\begin{array}{l}\text { Sensitivity } \\
\text { index }\end{array}$} & S1 & Tourism revenues as a share of GDP & 0.0585 & + \\
\hline & & S2 & Tourism growth elasticity coefficient & 0.0254 & - \\
\hline & & S3 & $\begin{array}{l}\text { Tourist foreign exchange income accounted for the } \\
\text { proportion of tourism revenue }\end{array}$ & 0.1123 & + \\
\hline & & S4 & $\begin{array}{l}\text { Tourist foreign exchange income accounted for the } \\
\text { proportion of foreign trade exports }\end{array}$ & 0.0771 & + \\
\hline & & S5 & The growth rate of total visitor Numbers & 0.0562 & - \\
\hline & & S6 & Tourist market concentration & 0.0684 & + \\
\hline & & S7 & The proportion of total tourism practitioners & 0.0909 & + \\
\hline & & & & & \\
\hline & \multirow{7}{*}{$\begin{array}{l}\text { Response } \\
\text { capacity } \\
\text { index }\end{array}$} & S1 & GDP per capita & 0.0503 & - \\
\hline & & S2 & Local financial self-sufficiency & 0.0889 & - \\
\hline & & S3 & Tourism revenue growth & 0.0230 & - \\
\hline & & S4 & Tourism overall Labor productivity & 0.0612 & - \\
\hline & & S5 & Diversity index of the industrial structure & 0.1490 & - \\
\hline & & S6 & $\begin{array}{l}\text { The actual use of foreign capital accounts for the city's } \\
\text { GDP }\end{array}$ & 0.0388 & - \\
\hline & & S7 & $\begin{array}{l}\text { The proportion of education expenditure of local fiscal } \\
\text { expenditure }\end{array}$ & 0.0998 & - \\
\hline
\end{tabular}

\section{The determination of index weight}

Due to the influence on tourism economy system vulnerability evaluation indexes, so it is necessary for each indicator weights assigned to, in order to reflect the effect degree of vulnerability. Entropy value method is based on the index of relative change extent of the impact of the system as a whole to calculate the index of information entropy, and then determine the index weight. Due to the impact tourism economy system vulnerability information is more, in order to make the weight has a certain degree of objectivity, therefore, using the entropy method to determine the tourism economy system vulnerability index weight, relatively more in line with the actual.

The main steps are as follows:

(1) Standardization of data processing. Due to the dimension of each evaluation index, an order of magnitude and indicators of positive and negative orientation difference, it is necessary to standardize the initial data processing, make the range of parameter values between the $[0,1]$. Index to evaluate the greater the target at the next higher level of support, adopt positive index calculation, such as the formula (1).

$$
X_{i p}^{\prime}=\left(X_{i p}-\min \left\{X_{p}\right\}\right) \div\left(\max \left\{X_{p}\right\}-\min \left\{X_{p}\right\}\right)
$$

(2) The smaller the index for evaluating the target support at the next higher level, the greater the calculation, the negative index such as formula (2).

$$
X_{i p}^{\prime}=\left(\max \left\{X_{p}\right\}-X_{i p}\right) \div\left(\max \left\{X_{p}\right\}-\min \left\{X_{p}\right\}\right)
$$

(3) The proportion $p$ of the year the $i$ item parameter values, its expression as formula (3).

$$
Y_{i p}=X_{i p}^{\prime} \sum_{i=1}^{m} X_{i p}^{\prime}
$$

(4)The information entropy of redundancy for indicators p, expression as formula (4).

$$
d_{p}=1-e_{p}
$$

(5)The weight for indicators p, expression as formula (5). 


$$
w_{p}=d_{p} \div \sum_{p=1}^{n} d_{p}
$$

In the formula (2), $X_{i p}$ said the case of a year I first $\mathrm{p}$ evaluation index, $\max \left\{X_{p}\right\}$ and $\min \left\{X_{p}\right\}$ respectively for the first year of all $\mathrm{p}$ indexes of maximum and minimum values, $\mathrm{m}$ years to evaluate the $\mathrm{n}$ as an index number.Of tourism economic system with the above methods, sensitivity and response to various indexes respectively in the calculation, the resulting vulnerability of the tourism economy system in China, the weight of each evaluation index.

\section{Conclusion}

In this paper, the tourism economy system vulnerability measure is based on the industry association and dynamic Angle of exploratory research, its research methods based on the financial fragility. Due to the fragility of the tourism economy system factor, species diversity, tourist economic vulnerability measure index types and the connotation definition is more complex, so the tourism economy system vulnerability of measure data specification, curve accuracy and universality still need further discussion.

\section{References}

[1] Wang, WenSheng, et al. "A new approach to water resources system assessment—set pair analysis method." Science in China Series E: Technological Sciences 52.10 (2009): 3017-3023.

[2] MENG, Xian-meng, and He-ping HU. "Application of set pair analysis model based on entropy weight to comprehensive evaluation of water quality [J]." Journal of Hydraulic Engineering 3 (2009): 002.

[3] $\mathrm{Hu}, \mathrm{Xiao}-\mathrm{xue}$, et al. "Set pair analysis model for river health system assessment." Systems Engineering-Theory \& Practice 5 (2008): 164-176.

[4] Su, M. R., et al. "Urban ecosystem health assessment based on emergy and set pair analysis—A comparative study of typical Chinese cities." Ecological modelling 220.18 (2009): 2341-2348.

[5] Pei-Yue, Li, Qian Hui, and Wu Jian-Hua. "Application of set pair analysis method based on entropy weight in groundwater quality assessment-a case study in Dongsheng city, Northwest China." Journal of Chemistry 8.2 (2011): 851-858. 